NBER WORKING PAPER SERIES

MANAGING CATASTROPHIC RISK

Howard Kunreuther

Geoffrey Heal

Working Paper 18136

http://www.nber.org/papers/w18136

\author{
NATIONAL BUREAU OF ECONOMIC RESEARCH \\ 1050 Massachusetts Avenue \\ Cambridge, MA 02138 \\ June 2012
}

The views expressed herein are those of the authors and do not necessarily reflect the views of the National Bureau of Economic Research.

NBER working papers are circulated for discussion and comment purposes. They have not been peerreviewed or been subject to the review by the NBER Board of Directors that accompanies official NBER publications.

(C) 2012 by Howard Kunreuther and Geoffrey Heal. All rights reserved. Short sections of text, not to exceed two paragraphs, may be quoted without explicit permission provided that full credit, including (C) notice, is given to the source. 
Managing Catastrophic Risk

Howard Kunreuther and Geoffrey Heal

NBER Working Paper No. 18136

June 2012

JEL No. D62,D80,D85,H20

\begin{abstract}
$\underline{\text { ABSTRACT }}$
A principal reason that losses from catastrophic risks have been increasing over time is that more individuals and firms are locating in harm's way while not taking appropriate protective measures. Several behavioural biases lead decision-makers not to invest in adaptation measures until after it is too late. In an interdependent world with no intervention by the public sector, it may be economically rational for those at risk not to invest in protective measures. Risk management strategies that involve private-public partnerships that address these issues may help in reducing future catastrophic losses. These may include multi-year insurance contracts, well-enforced regulations, third-party inspections, and alternative risk transfer instruments such as catastrophe bonds.
\end{abstract}

\author{
Howard Kunreuther \\ Operations and Information Management \\ The Wharton School \\ University of Pennsylvania \\ 3730 Walnut Street, 500 JMHH \\ Philadelphia, PA 19104-6366 \\ and NBER \\ kunreuther@wharton.upenn.edu \\ Geoffrey Heal \\ Graduate School of Business \\ 616 Uris Hall \\ Columbia University \\ New York, NY 10027-6902 \\ and NBER \\ gmh1@columbia.edu
}




\section{Managing Catastrophic Risk}

Howard Kunreuther

Geoffrey Heal

To Be Published in

\section{Encyclopedia of Energy, Natural Resources and Environmental Economics}

Economic and insured losses from catastrophes such as natural disasters and technological accidents have increased significantly in recent years. According to Munich Re (2012), economic losses from natural catastrophes alone increased from $\$ 528$ billion (1981-1990), \$1.2 trillion (1991-2000) to \$1.6 trillion over the period 2001-2011. During the past ten years the losses were principally due to hurricanes and resulting storm surge occurring in 2004, 2005, and 2008. Figure 1 depicts the evolution of the direct economic losses and the insured portion from great natural disasters over the period 1970-2011. ${ }^{1}$

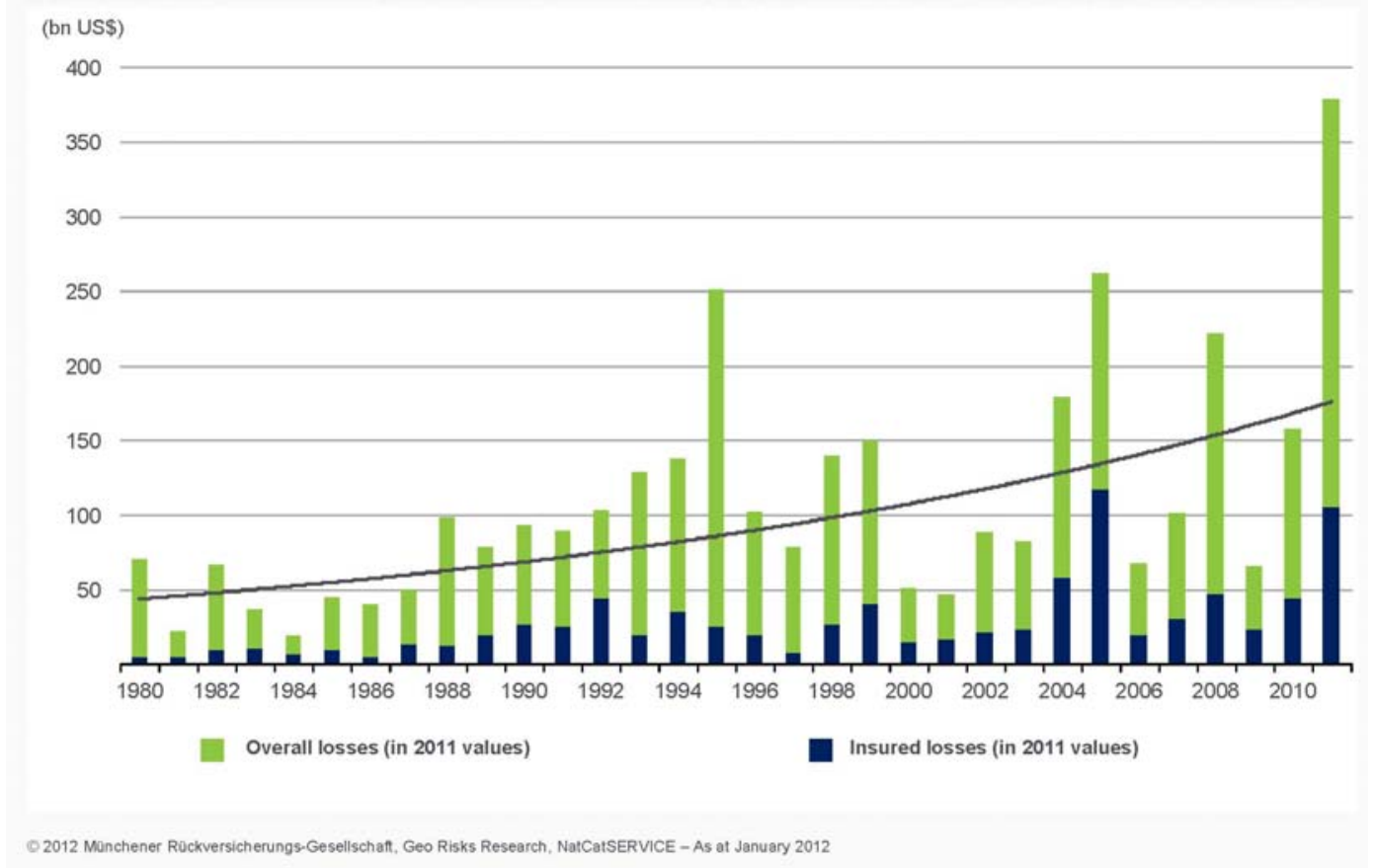

FIGURE 1. Natural Catastrophes Worldwide 1980-2011 - Overall and Insured Losses (\$ billion) Sources: Munich Re Geo Risks Research

\footnotetext{
${ }^{1}$ Catastrophes are classed as "great" if the ability of the region to help itself is overtaxed, making interregional or international assistance necessary. This is normally the case when thousands of people are killed, hundreds of thousands made homeless or when a country suffers substantial economic losses.
} 
Data on 2011 reveals that it is the most costly year that the insurance industry has every faced with respect to catastrophic losses. The Japan earthquake, tsunami and nuclear power plant accident in March 2011 caused over US\$210 billion in economic losses (not including nuclear-related damage), and insured losses in the range of US\$3540 billion (Munich Re, 2012). This disaster highlighted the interdependencies between natural and technological accidents. More specifically the 9.0 magnitude earthquake that struck the Tohoku region of northeastern Japan caused a tsunami that hit the country's coastline within half an hour, taking the lives of nearly 20,000 people and destroying over 100,000 buildings, including the cooling system and the back-up power generator of the Fukushima nuclear plant. The resulting meltdown of three nuclear reactors led to high radiation levels which required the evacuation of more than 60,000 people (World Economic Forum Global Risk Report, 2012).

A principal reason that losses from catastrophic risks have been increasing over time is that more individuals and firms are locating in harm's way while not taking appropriate protective measures. Section 2 focuses on the types of behavioural biases that lead decision-makers not to invest in adaptation measures until after it is too late. Section 3 shows that in an interdependent world with no intervention by the public sector, it may be economically rational for those at risk not to invest in protective measures. Section 4 proposes risk management strategies that involve private-public partnerships for addressing these issues and reducing future catastrophic losses. The paper concludes with suggestions for future research.

\section{Why Decision-Makers Do Not Invest in Protective Measures}

We now explore in more detail why decision-makers are reluctant to protect themselves against low-probability, high-consequence events. It is useful to begin by reviewing how protective decisions should ideally be made in a world where all decision-makers follow the economic rationality of utility maximization. We can then examine how biases, constraints and simplified decision rules foster actions that diverge from economic rationality.

Suppose that the decision-maker is considering incurring an investment that has potential payoffs for the next $T$ years and that there is an annual probability $p$ of a 
catastrophic loss in any given year $t$. We will denote as $B$ the annual benefit of investing in a measure that reduces the consequences of the disaster should such an event occur. ${ }^{2}$ In this case, the decision to protect against this event could be made by observing whether the upfront cost $(\mathrm{C})$ of the investment is less than the discounted stream of expected benefits $(p \mathrm{~B})$; that is, if

$$
C<\sum_{t=1}^{T}(p B) \beta^{t}
$$

where $\beta$ is the decision-maker's annual discount rate.

Implicit in (1) are three strong assumptions about how the decision-maker estimates and values costs and benefits over time. Specifically:

1) all future benefits are discounted exponentially

2) individuals can estimate future probabilities of a disaster

3) individuals can estimate the costs and benefits of the risk reduction measure

In practice, decision-makers are likely to utilize simplified choice rules, focus on constraints as well as short-run benefits and costs rather than discounting the future exponentially and may not consider probabilities in their decision on whether or not to invest in the risk-reduction measure (Kahneman and Tversky, 2000; Kunreuther, Meyer and Michel-Kerjan, in press).

\section{Budgeting Heuristics}

The simplest explanation as to why decision-makers may fail to invest in protection is affordability. If the decision-maker has limited capital on hand, there may be little point in undertaking a benefit-cost analysis of whether to incur the upfront cost of investing in protection.

Budget constraints may extend to higher income individuals if they have separate mental accounts for different expenditures (Thaler, 1999). Empirical evidence for this budgeting heuristic comes from a study where many renters indicated no change in their

\footnotetext{
${ }^{2}$ For simplicity, we are assuming only a single event in any year $t$ with a well-specified probability. The qualitative conclusions will not change if there are a number of possible events and probabilities vary over time. One could also make probabilities of a disaster in future years $t+n$ conditional on what happens in year $t$ to address issues of correlated risk.
} 
willingness to pay for a dead-bolt lock when the lease for the apartment was extended from 1 to 5 years. When asked why, one individual responded by saying:

$\$ 20$ is all the dollars I have in the short-run to spend on a lock. If I had more, I would spend more-maybe up to $\$ 50$ (Kunreuther, Onculer and Slovic, 1998, p. 284).

\section{Safety-first Behavior}

Decision-makers may utilize a simplified decision rule that determines whether to invest in protective measures only if the probability of the event $(p)$ is above their threshold level of concern $\left(p^{*}\right)$. If the decision-makers perceives $p<p^{*}$, then they will not

undertake any protection. If, on the other hand, $p>p *$ then they will want to invest in protection.

Should there be an opportunity to determine how much to invest in mitigating the consequences of the event, then the decision-maker may utilize a safety first rule by determining the optimal amount of protection so that $p \leq p$ *. This "safety first" rule initially proposed by Roy (1952) is utilized by insurers today in determining how much coverage to offer and what premium to charge against extreme events such as wind damage from hurricanes in hazard-prone areas (Kunreuther, Pauly and McMorrow, in press).

\section{Under-weighing the Future}

There is extensive experimental evidence revealing that human temporal discounting tends to be hyperbolic: temporally distant events are disproportionately discounted relative to immediate ones. As an example, people are willing to pay more to have the timing of the receipt of a cash prize accelerated from tomorrow to today, than from the day after tomorrow to tomorrow (in both cases a one-day difference) (Loewenstein and Prelec, 1992).

The implication of hyperbolic discounting for protective decisions is that decision-makers might be asked to invest a tangible fixed sum now to achieve a benefit later that they instinctively undervalue. The effect of placing too much weight on 
immediate considerations is that the upfront costs of protection will loom disproportionately large relative to the delayed expected benefits in losses over time.

\section{Myopic Behavior}

An extreme form of hyperbolic discounting is when the decision-maker considers only the expected benefits from the protective measure over the next year or two, rather than over the life of the protective measure. Elected officials are likely to view the decision by reflecting on how their specific decisions will affect their chances of re-election. If the perceived expected benefits from the measure achieved before their next re-election campaign are less than the costs of protection, they will very likely oppose the expenditure. They will prefer to allocate funds where they can see an immediate return. The fact that protective measures yield positive returns only when a disaster occurs makes it even more difficult to justify these measures. This reluctance to incur upfront costs that do not yield immediate benefits highlights a NIMTOF (Not in My Term of Office) behavior.

\section{Procrastination}

The tendency to shy away from undertaking investments that abstractly seem worthwhile is exacerbated if individuals have the ability to postpone investments - something that is almost always the case with respect to protection. A community might recognize the need to invest in irrigation measures to reduce the consequences of a disaster but may still fail to act.

A case in point with respect to lack of preparedness is demonstrated by the city of New Orleans and FEMA in advance of Hurricane Katrina in 2005. While emergency planners and the New Orleans Mayor's office were fully aware of the risks the city faced and understood the need for investments in preparedness, there was inherent ambiguity about just what these investments should be and when they should be undertaken. Faced with this uncertainty, planners did what decision-makers tend to do when faced with a complex discretionary choice: they opted to defer it to the future, in the (usually false) hope that the correct choices would become clearer and/or more resources would then be available (Tversky and Shafir, 1992). 


\section{Underestimation of Risk}

Another factor that has been shown to suppress investments in protection is underestimation of the likelihood of a hazard - formally, under-estimation of $p$ in (1). For one thing, decisions about protection are rarely based on formal beliefs about probabilities. Magat, Viscusi and Huber (1987) and Camerer and Kunreuther (1989), for example, provide considerable empirical evidence that individuals do not seek out information on probabilities in making their decisions. In a study by Huber, Wider and Huber (1997), only 22 percent of subjects sought out probability information when evaluating risk managerial decisions. When asked to justify their decisions on purchasing warranties for products that may need repair, consumers rarely use probability as a rationale for purchasing this protection (Hogarth and Kunreuther, 1995).

There is also evidence that people tend to simply ignore risks when the likelihood is small enough. In laboratory experiments on financially protecting themselves against a loss by purchasing insurance or a warranty, many individuals bid zero for coverage, apparently viewing the probability of a loss as sufficiently small that they were not interested in protecting themselves against it (McClelland et al. 1993; Schade et al., 2011). Many homeowners residing in communities that are potential sites for nuclear waste facilities have a tendency to dismiss the risk as negligible (Oberholzer-Gee, 1998).

Even risk experts disregard some hazards. After the first terrorist attack against the World Trade Center in 1993, terrorism risk continued to be included as an unnamed peril in most commercial insurance policies in the United States. Insurers were thus liable for losses from a terrorist attack without their ever receiving a penny for this coverage (Kunreuther and Michel-Kerjan, 2004). Following the attacks of September 11, 2001, insurers and their reinsurers had to pay over $\$ 35$ billion in claims due to losses from the terrorist attacks, at that time the most costly event in the history of insurance worldwide, now second only to Hurricane Katrina. 


\section{Impact of Interdependencies on Investing in Protective Measures}

In an interdependent world, the risks faced by any agent, whether an individual, organization or country, depend not only on that agent's own choices but also on the choices of others with whom the agent is linked. The economic incentive for an agent to invest in risk reduction therefore depends on how he or she expects the others to behave. The probabilistic nature of risks, and the fact that the risk which one agent faces is often determined in part by the behavior of others, gives a unique and complex structure to the incentives that interdependent agents face to reduce their exposures to risks. This has been called interdependent security (IDS) (Kunreuther and Heal 2003, see also Heal and Kunreuther 2007).

Often, the incentives for agents to invest in risk management will be compromised if they can be damaged by the failure of their peers to follow suit. The negative externalities caused by a weak link can have severe repercussions for everyone in an interconnected system. If there is a way to induce a few key players to take protective actions to reduce contamination of others sufficiently, this can lead to cascading and tipping where everyone invests in protection. Tipping and cascade have been documented in many contexts (Schelling, 1978; Dixit 2003; for a theoretical framework see Heal and Kunreuther 2010a)

The types of interdependencies are highlighted by the following scenarios which require coordination between firms and/or nations:

Baggage Transfer Security. Consider the destruction of Pan Am flight 103 in 1988. In Malta, terrorists checked a bag containing a bomb on Malta Airlines, which had minimal security procedures. The bag was transferred at Frankfurt to a Pan Am feeder line and then loaded onto Pan Am 103 in London's Heathrow Airport. The transferred piece of luggage was not inspected at either Frankfurt or London, the assumption in each airport being that it was inspected at the point of origin. The bomb was designed to explode above 28,000 feet, a height normally first attained on this route over the Atlantic Ocean. Failures in a peripheral part of the airline network, Malta, compromised the security of a flight leaving from a core hub, London. 
Risk of Power Failures. Consider a utility that is part of a power grid. The utility wants to determine whether to invest in additional capacity or security measures (e.g., trimming vegetation near distribution lines) to reduce the chance of a power failure. In such a highly interdependent system, there is a systemic tendency to under-invest in reliability. As a consequence of the interdependency, part of the cost of a failure, perhaps a large part, is passed on to competitors and their customers. In the case of the August 2003 power failures in the northeastern U.S. and southeastern Canada, the costs of a failure at an Ohio utility, were passed on to other utilities and customers in the grid (Feinstein 2006).

Meltdown of a Nuclear Reactor. Consider a group of small adjacent countries (for example, Belgium, Holland and Luxembourg, or Latvia, Lithuania and Estonia) so that a meltdown in a nuclear power plant in one of those countries will lead to massive radioactive contamination in all of them. It is reasonable to assume, then, that the loss to any country from a meltdown is catastrophic and would not be worsened by an additional nuclear reactor accident.

The presence of another country that has not invested in reactor safeguards reduces the incentive to protect one's own reactor because a meltdown elsewhere can damage a country as much as a meltdown at home. However, this is relevant only if the country does not suffer a loss as a result of its own reactor's failure. By investing in protection a country reduces the risk it faces domestically, but increases the chance of damage originating elsewhere from countries that have not invested in reactor safeguards.

\section{Risk Management Strategies}

Individuals' behavioral biases and misperception of the risks, combined with negative externalities caused by interdependencies, may be ameliorated by private-public partnerships designed to deal with catastrophic risk. Several such options are discussed below. 


\section{Multi-Year Contracts with Well-enforced Regulations and Short-Term Incentives}

As discussed above, individuals significantly discount long-term future returns, leading to a reluctance to invest in costly risk-reducing measures, because the upfront costs far exceed the short-run benefits. Short-term economic incentives may encourage long-term planning to manage extreme events. Some examples are :

(1) Well-designed and well-enforced regulations to reduce the likelihood of a catastrophic event and to ensure preparedness for recovery. If British Petroleum had adhered to the regulations by the Minerals Management Service (U.S. Department of the Interior), the 2010 Gulf Coast disaster may have been avoided or mitigated. If building codes had been well enforced in Florida, over one-third of the damage from Hurricane Andrew in 1992 could have been averted.

(2) Long-term financial responsibility for investing in mitigation. Decisionmakers will have a greater economic incentive to invest in mitigation if the results of these investments are measured over time. These incentives could take the form of contingent bonuses, reduced taxes and/or subsidies for several years.

(3) Short-term incentives to reward individuals and firms for taking these measures. This could take the form of reduced insurance premiums coupled with loans for undertaking a protective measure.

One area that might benefit from such incentives is the challenge in managing the risk of flooding in hazard-prone areas where residents show little interest in either purchasing insurance or investing in loss reduction measures.

A multi-year insurance contract attached to the property, not to the individual, would provide property owners currently residing in flood-prone areas with a fixed inflation-corrected annual premium for a designated time period (e.g., five, ten, or twenty years). If long-term loans for flood mitigation were offered by banks, then individuals with multi-year flood insurance policies might be encouraged to invest in cost-effective loss reduction measures. Those measures could reduce future losses and hence insurance claims, providing a rationale for lower premiums over the length of the insurance 
contract. If the loss reduction measures were cost-effective, then the reduction in the annual insurance premium would be greater than the annual cost of the loan.

For example, if a property owner with a 10-year flood insurance policy were able to obtain a 10-year home improvement loan to invest in risk-reducing measures, the result could be a reduction in catastrophic losses. Supporting mechanisms would be important as well, such as inspections by qualified third parties to make sure that the mitigation measure is undertaken .

\section{Coordination Policies to Deal with Interdependencies}

Coordination between individuals and/or firms is important to deal with problems of interdependencies. The form of coordination will differ depending on the nature of the risk and the type of interdependency. With respect to baggage transfer security, a trade association can play a coordinating role by stipulating that all members must follow certain rules and regulations, including the adoption of security measures. Prior to 9/11, the International Air Transport Association (the association to which most airlines belong), could have required all bags to be checked through a formal screening process. Each airline could have agreed that it would not accept in-transit bags from airlines that did not adhere to this regulation. Of course, following $9 / 11$, airports undertook the role of coordinating baggage security, although there still may be weak links in the system.

With respect to chemical accidents, a study by the National Academy of Sciences (2005) focused on reducing vulnerabilities in the chemical infrastructure when there are weak links in the system and there is the possibility of contamination by others. More specifically, the passage of Section 112(r) of the Clean Air Act Amendments (CAAA) of 1990 required facilities to perform a hazard assessment, estimate consequences from accidents and submit a summary report to the U.S. Environmental Protection Agency (EPA) called the Risk Management Plan (RMP). Regulatory agencies, such as the EPA, are struggling as to how to encourage compliance with these regulations given their limited personnel and funds for auditing facilities.

Chemical firms, particularly smaller ones, have little financial incentive to follow centralized regulatory procedures if they estimate that the likelihood of their being inspected by a regulatory agency is very small and/or they know the fine will be low. In 
such cases, they may be willing to take their chances and incur the fine should they be caught violating the existing rules. This is analogous with the decision on whether to put money in a parking meter. If you know that the chances of a meter being checked are very small and the fine is relatively inexpensive, then you might think twice before parting with your quarters.

Delegating part of the inspection process to the private sector through insurance companies and certified third party inspectors would create a means though which the low-risk units can speak for themselves. If units which are inspected receive a "seal of approval," that unit ought to be rewarded with a lower insurance premium than one not managing its risks. If a unit chooses not to be inspected by certified third parties, it is more likely to be a high-risk rather than a low-risk one, and the regulatory agency can devote its limited resources to auditing these facilities (Kunreuther, McNulty and Kang, 2002). As the probability of being audited by a regulatory agency increases, there is an incentive for the high-risk firm to adopt risk management plans for much the same reason that parking meters become more effective if one knows the likelihood of being fined is high.

\section{Liability and Insurance for Dealing with Nuclear Risks ${ }^{3}$}

In the United States, the Price-Anderson (P-A) Act provides insurance coverage to public utilities and transfers significant liabilities from a nuclear power plant accident to the Federal Government. If the use of nuclear power expands in the next decade, as may be the case, then these liabilities could increase further. Although it is clear that the contingent federal liabilities associated with P-A are large, it is hard to be precise about them.

There are, however, certain things that are clear. One is that to some degree. the risk is under the control of the Federal Government via the Nuclear Regulatory Commission if it enforces safety standards and influences the siting of nuclear reactors in remote areas. There is empirical evidence that the NRC does not aggressively pursue and

\footnotetext{
${ }^{3}$ This section is based on Heal and Kunreuther (2010b).
} 
penalize mismanagement of nuclear power stations, and that Federal authorities are not sensitive to the increase in potential costs associated with siting near densely populated areas. There is scope for better management of this aspect of Federal financial risks, possibly by the use of third-party safety auditors to supplement the NRC. In addition, the premiums charged to utilities under the P-A Act do not reflect their facilities' safety risks: this would be another way of reducing the risk of a disaster. Currently, there are few incentives for a utility to improve its safety record.

There do seem to be compelling reasons for thinking that Federal intervention is necessary if the risk of nuclear disaster is to be adequately insured. Typical of this risk and others where there is a potential for catastrophic losses, a first insurance layer is covered by private insurance markets, with government coverage of losses in excess of the private risk cap. This is true of terrorism insurance and earthquake insurance in California. In the case of the P-A Act, the private coverage is just $\$ 300$ million per incident, with a pool insurance vehicle covering the next $\$ 10$ billion. There is no explicit statement of the government's role and liabilities. The $\$ 300$ million surely does not exhaust the private sector's available capital for covering losses from a nuclear power plant accident. More of the nuclear risk could surely be met through the private sector, which would not only reduce the Federal liability but also provide increased incentives for risk management, sadly lacking under the current regime.

\section{Using Alternative Risk Transfer Instruments for Covering Catastrophic Losses ${ }^{4}$}

To deal with catastrophic losses, some governments are considering the use of dedicated financial products to supplement traditional insurance and reinsurance products. The development of alternative risk transfer (ART) instruments grew out of a series of insurance capacity crises in the 1970s through the 1990s that led purchasers of traditional reinsurance coverage to seek more robust ways to buy protection. Although ART instruments comprise a wide range of products, we focus here on the use of catastrophe bonds that transfer part of the risk exposure directly to investors in the financial markets.

\footnotetext{
${ }^{4}$ This section is based on Michel-Kerjan, Zelenko, et al. (2011).
} 
This financial instrument has increased in volume in recent years and is likely to continue to grow as the world experiences more costly catastrophes in the coming years.

How Do Catastrophe Bonds Work? Catastrophe bonds ("cat bonds") can enable a country, a company or any organization to access funds from investors if a severe disaster produces large-scale damage. Consider a country, Proactive, which would like to cover part of its exposure against catastrophes. To do so, it creates a company, BigCat, whose only purpose is to finance the disaster costs of Proactive. Notably, BigCat is not a government-run company but an independent company. In that sense, BigCat is a single purpose insurer (also called a special-purpose vehicle, or SPV) for Proactive. When the insurance contract is signed, the sponsor (Proactive) pays premiums to BigCat. SPV BigCat raises the capital to support its insurance policy by issuing a bond to investors. Premiums collected from Proactive will be used to provide the investors with a high enough interest rate to compensate for a possible loss of their principal should a disaster occur. Figure 2 provides the structure of a typical government cat bond.

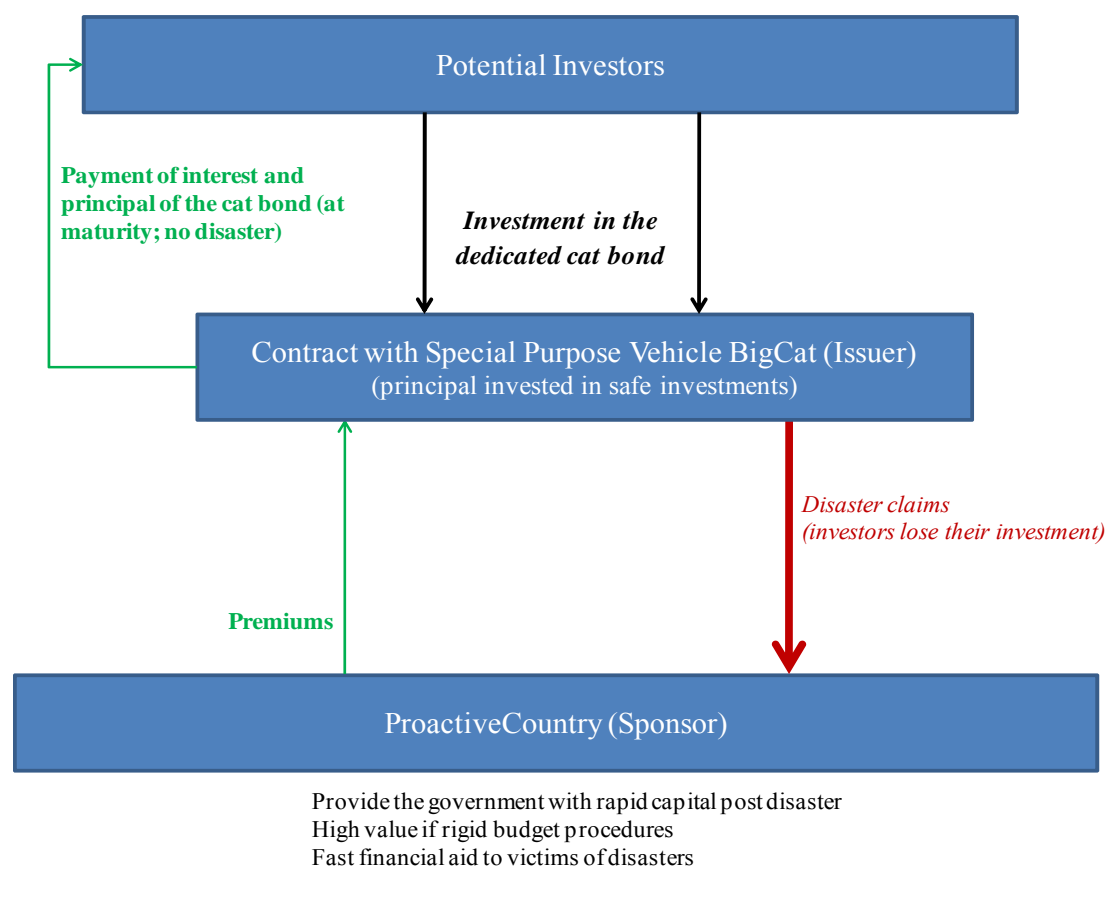

FIGURE 2. SIMPLIFIED STRUCTURE OF A GOVERNMENT CAT BOND 
How a government benefits from a cat bond. There are several ways the payment of a cat bond can be triggered. First, all the stakeholders can agree at the execution of the contract on an external trigger for the insurance payment, independent of the actual level of losses the country has suffered, but easily verifiable, similar to the rainfall trigger on index-based insurance. This is called a parametric trigger. The data for this parameter can be collected at multiple reporting stations across a given geographical area. It is also possible to agree on a certain level of the actual economic losses incurred by Proactive from a disaster or series of disasters over the maturity of the cat bond. This is an indemnity trigger. ${ }^{5}$ The main advantage of an indemnity trigger is that the payment received by Proactive will be much closer to its actual loss but it could create moral hazard problem by having the country overstate the loss it has incurred. Parametric cat bonds are more transparent and simpler to use and hence have been the preferred type in lesser developed countries.

Advantages of using a cat bond. There are several advantages of using a cat bond to provide protection against a catastrophic disaster. They are:

(1) Multi-year coverage and price stability. Insurance and reinsurance contracts are typically issued for one year and are subject to price increases particularly after a largescale disaster. ${ }^{6}$ Cat bonds offer an important element of stability for their users by guaranteeing a predefined price over several years. As of 2008, more than 170 cat bonds had been issued since 1996, and their average maturity has been three years with a few

\footnotetext{
${ }^{5}$ This form of cat bond trigger is more analogous to a traditional insurance policy with its loss settlement process. Other triggers are on modeled losses or industry losses. For modeled losses, instead of dealing with Proactive's actual losses, an exposure portfolio is constructed for use with catastrophe modeling software. When there is a disaster, the event parameters are run against the exposure database in the cat model. If the modeled losses are above a specified threshold, the bond is triggered. For industry losses, the cat bond is triggered when an entire industry loss from a certain peril for the insurance industry doing business in this country reaches a specified threshold.

${ }^{6}$ The Guy Carpenter Rate-on-Line index shows a 30 percent annual volatility over the past ten years. Premiums also differ markedly among perils that increase the concentration of risk to the reinsurers and perils which provide diversification. And it is not unusual to see reinsurance prices in a region increase by 20 to 50 percent after a major disaster. Catastrophe reinsurance prices in Florida increased by nearly 100 percent the year after Hurricane Katrina (Kunreuther and Michel-Kerjan, 2009, chapter 7).
} 
bonds being as long as five or ten years. Longer bonds reduce upfront costs by allowing fees to be amortized over a longer period of time (Michel-Kerjan and Morlaye, 2008).

(2) Guaranteed expedited payment. Another key advantage of a cat bond is that the money can flow to the government in just a few weeks. By design, the capital of the bond is commonly invested in risk-free assets, such as U.S. Treasury money market funds, so there is limited credit risk. ${ }^{7}$

(3) Potentially easier to manage politically than a government reserve. A typical financial policy tool for governments is to build up a reserve of money over time to be used in the case of a catastrophe. However, a catastrophe could occur in the very first years so that the fund simply does not have enough money to pay for the losses. If the country does not suffer major losses for a long period, attention fades and the reserves may be transferred to other programs particularly when budgets are tight. ${ }^{8}$ It is difficult to have a long-term perspective on these issues for reasons discussed above (MichelKerjan and Slovic, 2010). Cat bonds overcome these challenges, since the catastrophe portion of the risk is transferred to financial investors who serve as third parties.

\section{Conclusions}

Individual decisions regarding risk-reducing measures are influenced in fundamental ways by a set of biases and the behavior of others. In particular, the reliance on pure private market solutions that depend solely on individual initiatives may fail in these environments. Multi-year contracts and short term economic incentives may encourage decision-makers to invest in protective measures to reduce the losses from catastrophic risks. To address issues of interdependencies, coordinative mechanisms through trade associations and sharing best practices could promote actions that enhance individual and social welfare., Private sector initiatives, such as third-party inspections and insurance,

\footnotetext{
${ }^{7}$ Note that some reinsurers now provide collateralized reinsurance treaties as well, but those are more expensive than traditional reinsurance treaties.

${ }^{8}$ This was suggested in the United States for the Hurricane Relief Fund in Hawaii in 2009. Another example relates to the U.S. Pension Benefit Guaranty Corporation. In the 1990s there were interest groups lobbying the PBGC to reduce premiums because they were "too high," as evidenced by the fact that the PBGC was running a surplus.
} 
can be combined with actions taken by the public sector, such as well-enforced regulations and standards, to induce firms to adopt risk-reducing measures.

These could be important steps for reducing our vulnerabilities to potential catastrophes -- floods, hurricanes, earthquakes, terrorism threats, financial crises, oil spills and other extreme events waiting on the horizon. 


\section{REFERENCES}

Camerer, C., Kunreuther, H. (1989). “'Decision Processes for Low Probability Events: Policy Implications." Journal of Policy Analysis and Management, 8: 565-592.

Dixit, A. (2003). “Clubs with Entrapment.” American Economic Review 93:1824-29

Feinstein, J. (2006). In: Seeds of Disaster, Roots of Response: How Private Action Can Reduce Public Vulnerability. P. Auerswald, L. Branscomb, T. LaPorte, and E. Michel-Kerjan, (eds.) (2006) New York: Cambridge University Press.

Heal, G., Kunreuther, H. (2007). “Modeling Interdependent Risks” Risk Analysis, 27(3): $621-634$

Heal, G., Kunreuther, H. (2010a). "Social Reinforcement: Cascades, Entrapment and Tipping" American Economic Journal: Microeconomics, 2(1): 86-99

Heal, G., Kunreuther, H. (2010b). "Environment \& Energy: Catastrophic Liabilities” In: Measuring and Managing Federal Financial Risk. D. Lucas (ed.) University of Chicago Press, 2010.

Hogarth, R., Kunreuther, H. (1995). "Decision Making Under Ignorance: Arguing with Yourself," Journal of Risk and Uncertainty, 10: 15-36.

Huber, O., Wider, R., Huber, O. (1997). "Active Information Search and Complete Information Presentation in Naturalistic Risky Decision Tasks," Acta Psychologica, 95: 15-29.

Kahneman, D., Tversky, A. (2000). Choices, Values and Frames. New York: Cambridge University Press.

Kunreuther, H., Heal, G. (2003). "Interdependent Security" Journal of Risk and Uncertainty, Special Issue on Terrorist Risks, 26: 231-249.

Kunreuther, H., Meyer, R., Michel-Kerjan, E. (in press). "Overcoming Decision Biases to Reduce Losses from Natural Catastrophes," in E. Shafir (ed.), Behavioral Foundations of Policy, Princeton University Press.

Kunreuther, H.C., McNulty, P.J., Kang, Y. (2002). "Improving Environmental Safety Through Third Party Inspections.” Risk Analysis, 22(2): 309-18.

Kunreuther, H., Michel-Kerjan, E. (2004). "Challenges for Terrorism Risk Insurance in the United States.” Journal of Economic Perspectives, 18(4): 201-214. 
Kunreuther, H. Michel-Kerjan, E. (2011). At War with the Weather, MIT Press. (Paperback Edition)

Kunreuther, H., Onculer, A., Slovic, P. (1998). "Time Insensitivity for Protective Measures” Journal of Risk and Uncertainty, 16: 279-299.

Kunreuther, H., Pauly, M., McMorrow, S. (in press). Insurance and Behavioral Economics: Improving Decisions in the Most Misunderstood Industry. New York: Cambridge University Press.

Loewenstein, G., Prelec, D. (1992). Anomalies in intertemporal choice: Evidence and an interpretation. Quarterly Journal of Economics, 107(2): 573-597.

Magat, W., Viscusi,K. W., Huber, J. (1987). “'Risk-Dollar Tradeoøs, Risk Perceptions, and Consumer Behavior." In Learning About Risk, W. Viscusi and W. Magat (eds.). Cambridge, Mass.: Harvard University Press, 83-97.

McClelland, G., Schulze, W., Coursey, D. (1993). "Insurance for Low-Probability Hazards: A Bimodal Response to Unlikely Events," Journal of Risk and Uncertainty, 7: 95-116.

Michel-Kerjan, E., Morlaye, F. (2008). "Extreme Events, Global Warming, and Insurance-Linked Securities: How to Trigger the 'Tipping Point'." Geneva Papers on Risk and Insurance, 33(1): 153-176.

Michel-Kerjan, E., Slovic, P. (2010) The Irrational Economist. New York: Public Affairs Books

Michel-Kerjan, E., Zelenko, I., Cardenas, V., Turgel, D. (2011). "Catastrophe Financing for Governments: Learning from the 2009-2012 MultiCat Program in Mexico" OECD Working Papers on Insurance and Private Pensions. DOI: $\underline{10.1787 / 20797117}$

Munich Re (2012). Topics Geo Natural catastrophes 2011, Analyses, assessments, positions. http://www.munichre.com/publications/302-07225_en.pdf

National Academy of Sciences (2005). Assessing Vulnerabilites Related To The Nation's Chemical Infrastructure. Washington DC, The National Academies Press

Oberholzer-Gee, F. (1998). "Learning to Bear the Unbearable: Towards and Explanation of Risk Ignorance." Mimeo, Wharton School, University of Pennsylvania.

Roy, A.D. (1952). "Safety First and the Holding of Assets" Econometrica, 20:431-449 
Schade, C., Kunreuther, H., Koellinger, P. (2011). "Protecting Against Low-Probability Disasters: The Role of Worry." Journal of Behavioral Decision Making, DOI: $10.1002 / \mathrm{bdm} .754$

Schelling, T. (1978). Micromotives and Macrobehavior New York: Norton.

Thaler, R. (1999). “Mental Accounting Matters" Journal of Behavioral Decision Making, 12:183-206.

Tversky, A., Shafir, E. (1992). "Choice under conflict: The dynamics of deferred decision," Psychological Science, 3, 6, 358-361.

World Economic Forum (2012). Global Risks 2012 (Seventh Edition) 